\title{
Mais Populismo, Menos Representatividade: monitoramento e lógica populista da comunicação política em redes sociais online
}

\author{
Fernanda Cavassana de Carvalho e Emerson Urizzi Cervi
}

\author{
Fernanda Cavassana de Carvalho \\ Doutoranda em Ciência Política pela \\ Universidade Federal do Paraná (UFPR). \\ E-mail: cavassanaf@gmail.com

\section{Emerson Urizzi Cervi} \\ Professor associado do Departamento \\ de Ciência Política da Universidade Federal \\ do Paraná (UFPR). E-mail: ecervi7@gmail.com
}

\begin{abstract}
Resumo
Considerando uma dimensão discursiva do populismo enquanto fenômeno político, este artigo volta-se a debater como a lógica da comunicação online em rede potencializa características populistas das interações públicas e políticas representativas. Isto é evidenciado tanto nos fenômenos populistas, quanto nas manifestações de monitoramento e fiscalização das instituições democráticas. O objetivo do artigo é realizar uma aproximação da discussão sobre a comunicação populista com a teoria das democracias monitoradas, tendo como fio condutor a comunicação via redes sociais online (RSO). As características das relações entre representantes e representados nas duas perspectivas são articuladas por meio de uma revisão bibliográfica que considera uma literatura teórica clássica e alguns resultados de estudos empíricos recentes. Como notas conclusivas, o trabalho ressalta alguns pontos de convergência traçados ao longo do trabalho para evidenciar como a comunicação via RSO não só atende como potencializa a lógica populista da comunicação política e a crise de representatividade institucional nas democracias contemporâneas.
\end{abstract}

\section{Palavras-chave}

Populismo. Comunicação populista. Redes sociais online. Democracia monitorada.

\begin{abstract}
Taking into account a discursive dimension of populism as a political phenomenon, this article debates how the logic of online communication enhances features of populism on the public and political representative interactions. This is shown both on the populist phenomenon and on expressions of monitoring and inspection of democratic institutions. The article's objective is to realize an approximation of the debate of populist communication with the theory of monitory democracy, and for this, the communication on social networking sites is used as common thread. The features of relations between representatives and those represented on both perspectives are articulated through a bibliographic review which considers a classic and theoretical literature and some results of recent empirical studies. In conclusion notes, some common features discussed in the article are highlighted, like a way the communication on social media sites attends and enhances the logic populist of the political communication and the crisis of institutional representativeness in the contemporary democracies.
\end{abstract}

\section{Keywords}

Populism. Populist Communication. Social Networking Sites. Monitory Democracy. 
MAIS POPULISMO, MENOS

REPRESENTATIVIDADE: MONITORAMENTO

E LÓGICAPOPULISTA DA COMUNICAÇÃO

POLÍTICA EM REDES SOCIAIS ONLINE

Fernanda Cavassana de Carvalho Emerson Urizzi Cervi

\section{Introdução}

Este artigo discorre sobre aspectos das relações políticas a partir da comunicação em novos espaços que permeiam o debate contemporâneo, a saber, as redes sociais on-line (RSO). Esses ambientes comportam novos fluxos que garantem uma comunicação entre diferentes atores e instituições, do campo político e social, abarcando a comunicação entre representantes e representados. Defende-se aqui que, a partir dessas RSO, potencializa-se um tipo específico de construção política que se dá por meio de uma dimensão discursiva e retórica, o populismo. Assim, compreende-se que esse cenário digital tende a atender e a potencializar uma lógica populista das relações representativas no âmbito comunicativo.

O artigo tem como principal aporte teórico a discussão apresentada por Ernesto Laclau (2010) sobre a dimensão discursiva do populismo enquanto forma de construção política. A discussão teórica política sobre o populismo tem como premissa a quebra na confiança e representatividade das instituições. Essa perspectiva direciona o debate a perceber como isso acaba por se aplicar nas relações de representação digitais hoje, considerando o cenário que John Keane (2010) delimita como democracias monitoradas. Laclau e Keane se encontram ao falar da centralidade da crítica, em público, às instituições. Portanto, aqui o enfoque se dá na dimensão discursiva dessas relações, mostrando como a Internet e suas redes sociais se tornaram ambientes que podem potencializar as características comunicativas do populismo nas interações políticas e públicas.

Assim, o objetivo é realizar uma aproximação da discussão teórica sobre a comunicação populista com a teoria das democracias monitoradas, tendo como fio condutor a comunicação via redes sociais online (RSO). Por meio de uma revisão bibliográfica, as características das relações entre representantes e representados nas duas perspectivas são articuladas.

Considerando as ponderações de Kögl (2010) sobre o populismo ser um conceito aberto e sujeito a uma diversidade de abordagens teóricas e analíticas, opta-se aqui por estudar um único aspecto do fenômeno: a lógica de sua comunicação. A defesa de que o populismo pode ser compreendido como uma forma de comunicação já está presente na literatura política. Canovan (1999) integra o grupo dos autores que considera o populismo enquanto estilo comunicativo e não um tipo de ideologia. Essa perspectiva tem sido considerada por autores que passaram a analisar a comunicação de atores políticos, individuais ou coletivos, como os partidos, a partir de características do populismo, como se dirigir à população de forma massiva, explorando a retórica independentemente da vertente ideológica do discurso (JAGERS, WALGRAVE, 2005; COWLS, 2017; ERNST et al., 2017; BLOCK, NEGRINE, 2017). Pertinente a isso, neste artigo, o avanço é aproximar a discussão sobre a comunicação populista com a perspectiva de monitoramento das democracias, que também considera a dimensão comunicativa relevante e discorre sobre as cobranças e insatisfações com as instituições representativas.

O artigo está organizado em outras quatro seções. Primeiramente, dissertamos sobre o conceito do populismo, suas diferentes abordagens analíticas e as possíveis dimensões que ele apresenta e que podem ser aprofundadas enquanto fenômeno político. A segunda seção aprofunda-se na discussão de Laclau (2010) que, a partir da literatura sobre as massas, discorre sobre como a dimensão discursiva do populismo leva a uma relação entre representantes e representados ausente do uso da racionalidade.

O terceiro tópico explora como essas características aprofundadas por Laclau (2010) se manifestam a partir de uma lógica populista da comunicação (ENGESSER et al., 2017) e como a Internet potencializa as mesmas em diferentes dimensões. Apresenta-se também a teoria de Keane (2010) sobre as democracias monitoradas e as preocupações do autor com o cenário de abundância comunicativa, de informações e manifestações proferidas e consumidas. Para ele, o intenso monitoramento dos representantes pode ser prejudicial às democracias, levando a um desgaste da representação. Na seção final, são apresentadas conclusões que ressaltam os principais pontos 
discorridos ao longo do trabalho e defendem a articulação entre as perspectivas do monitoramento das instituições representativas e a lógica populista na comunicação.

\section{Populismo: o fenômeno, suas características e dimensões}

"Populismo" é um termo ambivalente e indeterminado (FUNES, 2014: p. 189) sobre o qual não há um consenso conceitual (HERMET, 2003). Trata-se de um conceito aberto e vago, muitas vezes utilizado para ilustrar os mais diversos fenômenos, inclusive contrastantes (KÖGL, 2010). Também já foi compreendido apenas como uma síndrome política, que apresenta um conjunto determinados de elementos relacionados a ideologias e instituições, além de representar diversos espaços e temporalidades (HERMET, 2003). Assim, a ideia de populismo acaba abrangendo distintos fenômenos, passando a ser utilizada para caracterizar desde formas de liderança, tipos de regimes políticos e de Estados, a tipos de partidos e movimentos políticos e ideológicos (FUNES, 2014: p. 187). Como estratégia política, então, o populismo se caracteriza, principalmente, por se dar por meio de um líder personalista e carismático que busca o poder ou, já o tendo adquirido, exerce-o com base em apoio popular direto, não institucionalizado, nem mediado. Geralmente, esse líder possui um grande número de seguidores, grande parte deles não organizados socialmente (WEYLAND, 2001: p. 14), o que leva à ideia de massa.

Hermet (2003) destaca que é típica do populismo a relação direta entre a massa e o líder, sem níveis intermediários de representação - como os partidos -, e a expectativa da concretização rápida dos objetivos prometidos. Um fenômeno populista tende a surgir em sociedades em que há crises de representatividade institucional e abertura para o surgimento desse líder, que se apresentará como carismático, disposto a suplantar essa representatividade de forma imediata. Dessa liderança, destaca-se ainda a capacidade retórica de articular o discurso e, nele, representar demandas. Das ponderações sobre o conceito presentes em Hermet (2003), destaca-se a característica de resiliência do fenômeno populista, que é múltiplo e flexível o suficiente para poder representar povos distintos, em situações distintas. Por isso, pode-se considerar que se trata de um fenômeno de transição, intrínseco ao processo histórico político de um país.

Na perspectiva de outros autores, Ernesto Laclau é visto como o teórico que defenderá o populismo como uma forma de construção da política (HERMET, 2003; KÖGL, 2010). Laclau (2010) pleiteava o populismo enquanto retórica de confrontação social, opondo a elite dominante à massa. Para ele, populismo acaba caracterizando diversas articulações políticas, da massa e das elites, da esquerda e da direita, dos conservadores e dos liberais. Ainda que cada um dos movimentos, líderes e fenômenos considerados populistas na história tenham suas especificidades, de modo geral eles apresentam pontos em comum.

Segundo Laclau (2010), além das particularidades de cada um dos fenômenos, podem ser observadas semelhanças em ao menos três dimensões. Em uma dimensão social, o populismo caracteriza-se pela não-institucionalização, pela polarização e pela divisão da sociedade em ao menos duas classes: a elite e o povo. Do aspecto temporal, é marcado pelo caráter de imediatismo, como já ressaltado a partir de Hermet (2003). Já na dimensão discursiva, o populismo abarca questões de retórica, podendo impor discursos unificadores ou separatistas.

$\mathrm{Na}$ busca por um conceito concreto e intrínseco ao populismo, Hermet (2003) problematiza a literatura específica sobre o tema, expondo diversas citações que buscam definir o que é o populismo, mas que falham ao generalizá-lo e relacioná-lo ou somente à vontade popular ou à existência de um líder carismático. As definições exploradas pelo autor são abrangentes, muito próximas do próprio conceito de democracia. Pertinente $a$ isso, cabe ressaltar que não há divergências entre autores apenas para uma definição do conceito, mas também a relação do populismo com a própria democracia, podendo compreendê-lo, por um lado, como um processo político essencialmente democrático ou, por outro, autoritário, exclusivamente anti-democrático. Para Abts e Rummens (2007), essa contradição é consequência da ambiguidade que o próprio conceito de democracia constitucional carrega e se deve à forma como ele será empregado: sob um viés mais participativo ou institucionalizado.

Os defensores do populismo conceituam a democracia em primeiro lugar como o domínio direto do povo e, portanto, tendem a identificar o populismo com a democracia. Os oponentes do populismo, por outro lado, mantêm uma concepção mais constitucional da democracia, enfatizando a importância da 
representação, dos direitos individuais e do equilíbrio de poderes e interesses (ABTS, RUMMENS, 2007: p. 406, tradução nossa)i.

Segundo os autores, o ideal é a compreensão de que há dois pilares, destinados a atenderem a diferentes objetivos e que, combinados, amparam a democracia. Enquanto um é constitucional e sustenta as regras e as instituições do jogo democrático, o outro é participativo, voltado para os cidadãos e para a sua soberania popular. Para Abts e Rummens (2007), o populismo se constituirá e se localizará num espaço existente entre um pilar democrático e outro. Portanto, articulado à ideia de democracia, é um fenômeno possível de ocorrer nos sistemas democráticos, mas sem substituir suas regras.

Essa perspectiva é compartilhada por Canovan (1999), que relaciona positivamente a ideia de populismo à de democracia. Para ela, o populismo é latente nas democracias e, nestas, sempre haverá espaços para ele. A autora inglesa defenderá que os fenômenos contemporâneos populistas - ainda que muitas vezes não reconhecidos como tal - podem representar o apelo do povo contra as instituições e expor suas demandas. Já Hermet (2003) aponta que o que pode definir um fenômeno como populista é o seu caráter antipolítico, que se direciona - por meio da dimensão discursiva - a uma promessa controversa para atender às necessidades populares. Nesta perspectiva, por mais que não seja institucionalizado, o populismo não deixa de ser uma ação política concreta, sustentada, inclusive, pelo apoio popular. Portanto, não se pode dizer que no populismo há necessariamente uma rejeição do princípio de representação em sua totalidade. A ideia de representatividade muitas vezes é imposta, inclusive, de modo afetuoso. $\mathrm{O}$ que se destaca no fenômeno é a contrariedade às formas institucionalizadas de representação.

Assim, das perspectivas teórica e empírica, a literatura tem refletido essa ambivalência e vacuidade sobre a definição e investigação do populismo. Kögl (2010), por exemplo, problematiza os estudos sobre o tema por, muitas vezes, apresentarem discussões genéricas além de, em alguns casos, componentes analíticos e teorias contrastantes. Na área, Hermet (2003) ressalta a relevância do empirismo, uma vez que o populismo se dá de modo analítico, distante do campo teórico. $\mathrm{O}$ autor reforça que ainda são escassos os estudos ${ }^{\text {iii }}$ que apresentam uma hipótese teórica pré-definida e gerem resultados por meio de aproximações.

Em suma, para o que nos interessa aqui, o conceito de populismo é discutido a partir de dois eixos centrais. O primeiro é quanto ele contribui ou corrói a democracia. Aqui, consideramos que a discussão não se aplica ao conceito geral de democracia, mas sim a um tipo específico de democracia, que é a democracia representativa. Por democracia representativa entendemos aquele modelo aplicado a sociedades nas quais existem instituições especializadas em fazer a representação das demandas sociais na esfera política. Assim, o bom funcionamento da democracia representativa passa pela capacidade que essas instituições (parlamentos, partidos políticos, entre outras) têm de representar as demandas sociais. Quando as instituições deixam de ser ponte e se transformam em muro que impede a transmissão das demandas sociais à arena política, a democracia representativa deixa de ser funcional e abre espaço para outros tipos de representação, entre elas a representação direta, via contato permanente entre líder e liderados, sem a intermediação das instituições convencionais.

$O$ segundo diz respeito à forma como se manifestam as preferências por representação:

discursiva. É pela via do discurso público que representados descontentes com o sistema político manifestam inicialmente uma projeção na liderança nova, no outsider, naquele que não representa a manutenção das instituições representativas. Só depois é que as projeções discursivas se materializam em movimentos políticos, golpes populares ou vitórias eleitorais dos novos representantes do povo. É essa dimensão que discutiremos a seguir.

\section{A dimensão retórica e a razão populista em Laclau}

Como apresentado no tópico anterior, para Ernesto Laclau (2010, p. 24) o populismo é uma forma de construção da política, essencialmente transitória e marcada pela articulação discursiva. Por

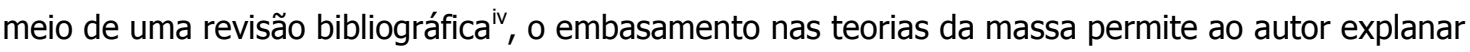
sobre como a compreensão do que é o populismo se degenerou a uma anomalia à democracia 
representativa. Para Laclau (2010), a perspectiva da teoria das massas indicou uma distinção muito forte entre o "normal" e o "patológico" na sociedade, como ocorreu com o conceito do populismo. 0 autor demonstrará como se desenvolveu o elitismo político, cujo apelo às instituições e às elites conduziu a uma compreensão negativa das massas, ao entendimento de que a "multidão" constituía-se em uma patologia social. O patológico para os elitistas é o novo e, neste caso, tudo aquilo que agride a capacidade de organização da sociedade de cima para baixo, da elite para a massa.

A discussão trazida por Laclau (2010) sobre o populismo é pertinente aos autores que criticaram a constituição da sociedade em massa pela descaracterização dos indivíduos sociais. Também é exposto como a discussão sobre a dimensão discursiva do populismo o reduziu a uma concepção simplista de "retórica". Quando perde a consistência pela ausência da ideologia, tornando-se apenas mero discurso retórico, o populismo passa a ser compreendido como efêmero, superficial e temporário para os elitistas críticos. Para que haja essa clara distinção entre ideologia e retórica, esta é entendida como o uso estratégico e adornado da linguagem, em sentido puro, sem vínculos ao conteúdo proferido. Já a ideologia está vinculada de modo mais aprofundado às preposições políticas dos movimentos. É por isso que, uma vez desvinculado do sentido, apenas restrito ao formato, o discurso político pode não assumir um caráter centrado na racionalidade (LACLAU, 2010).

No discurso político a ausência de sentido, o uso de símbolos vazios e a imprecisão daquilo que é difundido reforçam o ato performativo e conduzem à falta de identidade com a imagem social traçada. Contudo, Laclau (2010) destacará como isso se torna recorrente na esfera política e pública transformando-se num estilo de "racionalidade social" ampliada mas, contundentemente, a-racional. Em outras palavras, aquilo que é considerado a-racional torna-se consequência de uma mudança de comportamento e avaliação dos representados em relação ao que eles esperam dos representantes. A partir disso, Laclau $(2010$, p. 28) reforçará que o populismo - enquanto estilo retórico - torna-se uma opção viável e disponível de construção da política. Não sendo, portanto, entendido como um discurso vago, anormal à democracia e manipulativo.

Ao ressaltar o uso de discursos - compreendendo-os como conjuntos estruturados de articulações de elementos linguísticos e não linguísticos -, Laclau (2010, p. 27) também confere importância às sequências discursivas por meio das quais os movimentos sociais exercem sua ação política. Nesta abordagem, defende-se a capacidade de mobilização por meio de palavras que, às vezes desassociadas de seus significados, invocam imagens que influenciam a multidão. Laclau (2010) descreve que, muitas vezes, as palavras cujos significados são imateriais - como democracia, igualdade, liberdade - são aquelas que têm maior capacidade de mobilização.

No discurso, além da instabilidade na relação entre significantes e significados, destaca-se que a força de associação entre palavras e imagens influi na exclusão do uso da racionalidade nas relações políticas e públicas, pois a razão e os argumentos são incapazes de superar a comunicação imagética. Destaca-se que a retórica requer alguns recursos fundamentais como: repetição, afirmação e contágio - sendo que estes atuam diretamente na eliminação da racionalidade nessa forma de comunicação (LACLAU, 2010).

Além disso, para Hermet (2003) há um aspecto de demagogia que desacredita o discurso populista pelo conteúdo, não apenas pela performance. Para o autor, os líderes populistas se apresentam como autores de resoluções imediatas, mas inviáveis. É por meio de um estilo próprio de comunicação política que a liderança defenderá sua capacidade de atender as esperanças de soluções sociais da massa, obtendo confiança dela. Para que haja, portanto, esse elo entre o discurso gerido e a população sobre a qual ele terá efeito, é necessária a identificação mútua.

Muitas vezes, as ideias articuladas retoricamente pelo discurso populista podem ser absorvidas nos mais variados contextos culturais - uma vez que importa mais seu caráter performativo enquanto retórico do que o seu conteúdo - e, por isso mesmo, mudam de significado de acordo com o ambiente em que estão inseridas. Entre os aspectos performativos que podem ser verificados, ressalta- 
MAIS POPULISMO, MENOS

REPRESENTATIVIDADE: MONITORAMENTO

E LÓGICAPOPULISTA DA COMUNICAÇÃO

POLITIICA EM REDES SOCIAIS ONLINE

Fernanda Cavassana de Carvalho Emerson Urizzi Cervi

se a relativa simplicidade do discurso (CANOVAN, 1999), discurso esse que, para Laclau (2010), por mais que soe como vago, pode exemplificar o nível de racionalidade da realidade social que reflete. Ou seja, para o autor, antes de procurarmos qualificar ou desqualificar o objeto em questão, devemos nos questionar se o aspecto vago do discurso populista não é consequência e reflexo de situações vagas e indeterminadas da própria realidade social em que ele é proferido e articulado. Por isso, não se deve confundir a ausência o uso da racionalidade na comunicação política populista em Laclau (2010) com incapacidade do uso da razão ou irracionalidade dos atores envolvidos nesta comunicação.

Laclau (2010: p. 33) problematiza também a compreensão de que o populismo, de maneira negativa, simplifica o espaço público. A existência de dicotomias na sociedade (e.g., povo versus oligarquia; trabalhadores versus empresários) é reforçada como uma condição própria da ação política e não algo restrito ao processo ou fenômeno populismo. Ao discorrer sobre isso, Laclau considera as proposições de Freud, o qual compreende um enfoque mais complexo e promissor para compreender a organização pública em grupos e a transferência de confiança aos representantes. É na abordagem freudianav que Laclau afirmará que desaparecem os vestígios do dualismo, presentes nas obras sobre as massas. $O$ autor indicará que, por mais que sempre haja diferenças entre a definição de "públicos" e a "multidão", os grupos sociais também se baseiam e se constituem segundo uma lógica de homogeneização, a partir das semelhanças. E isso ocorre por meio da identificação entre os dois grupos.

O afeto passa a ser uma dimensão importante aqui, por ele ser responsável, muitas vezes, por consolidar o elo entre os representantes e os representados. Por afeto entendemos a relevância de aspectos emocionais mais exacerbados, ou seja, tanto positivo entre o povo e o líder populista, quanto negativo, entre o povo e os "inimigos" do líder. É o afeto que explica a adesão da massa à imagem do líder, projetada enquanto tipo ideal, ressaltando, mais uma vez a ausência de racionalidade na relação, que assume um caráter muito mais subjetivo, baseada em emoções em detrimento da razão. A afeição pode se dar em diferentes níveis, inclusive na sociedade homogeneizada, em massa.

Segundo Laclau (2010: p. 87), é possível que isso gere diferentes relações sociopolíticas entre os grupos e seus representantes dependendo, principalmente, do grau de distância entre o "eu" e o "eu ideal" - este muitas vezes representado pela figura do líder. Se houver pouca distância, o líder surgirá do grupo, tornando-se o representante, mas ainda muito próximo e integrando os representados. Em suma, essa é a compreensão de Laclau (2010) a partir da teoria freudiana, que a relação com os liderados se dá por meio de uma identificação desses ao líder, idealizado. Desse modo, há uma transferência do "tipo ideal" ao líder populista, e isso será cobrado dele por esses seguidores.

A identificação dos grupos e a relação com o tipo ideal também pode levar a dois caminhos distintos, a depender do discurso que melhor se propagará, que gerará melhor resposta social. 0 discurso populista pode ser mais inclusivo, ao defender direitos comuns; ou mais excludente, quando apresentar apelos mais separatistas, contra "eles" (CANOVAN, 1999). Neste caso, o "nós" mobilizado pelo discurso é somente um grupo, uma parte da massa.

A partir dessa reflexão, vincula-se o discurso que deslegitima o populismo como fenômeno político àquele que é responsável pelo descrédito das massas. Em ambos estão, por exemplo, presentes argumentos de marginalidade, transitoriedade, retórica e manipulação (LACLAU, 2010: p. 88). A defesa pelas instituições e organização e estruturação social, consequentemente, soma-se às críticas nos dois casos e representa o discurso oposto ao populista.

Segundo a leitura de Kögl (2010), as abordagens discursivas como a apresentada por Laclau (2010) possibilitam uma alternativa para o estudo populista, porque trabalham o populismo como um tipo particular de articulação aplicável em quaisquer conteúdos políticos. É por isso que é relevante considerar o campo de formação do discurso, a realidade social em que está inserida, para que se compreenda a lógica daquela articulação. Como ressalva, Kögl (2010) discorre que, ao colocar o 
populismo como inerente à política, a perspectiva de Laclau dificulta a distinção analítica do que seria prática política - enquanto discursos articulados - daquilo que seria a própria comunicação populista.

Portanto, nesta abordagem, a disposição performativa do populismo é compreendida apenas como uma prática discursiva, renegando a ideia de relações causais entre os determinantes estruturais e as suas consequências populistas (KÖGL, 2010). Trata-se, pois, de um fenômeno conjuntural, não um objeto limitado. Assim, a partir de Laclau (2010) e Kögl (2010), espera-se que pesquisas voltadas para a dimensão discursiva da comunicação populista considerem as pré-condições sociais e estruturais para a sua existência, uma vez que não há uma unidade referencial delimitada.

Um ponto relevante ao abordar o fenômeno do populismo pela sua característica discursiva é a necessária separação entre populismo e personalismo, pois são dimensões distintas, ainda que ligadas ao mesmo fenômeno político. O discurso no populismo é aquele que se faz em nome de e para o povo. Além disso, o discurso populista não é necessariamente originário no povo. Pode ser popular e populista ao mesmo tempo, mas nada impede que integrantes de uma elite social, econômica ou intelectual construam um discurso dirigido diretamente ao povo e em nome dele. $E$ isso é diferente da relação personalista entre líder e liderado, enquanto tipo de representação vinculada mais à figura individual de um ator político do que de partidos e plataformas políticas e baseada em comunicação não mediada entre representante e representados (MANIN, 1997). Personalismo e populismo, portanto, distinguemse, mas se complementam. $O$ descrédito das instituições representativas leva à relação personalista entre representante e representado e isso permite a difusão de discursos populistas. Acerca disso, a próxima seção deste artigo discorrerá sobre como essa lógica comunicativa se constitui e como suas características podem ser potencializadas pelas interações na Internet, em especial pelos fluxos comunicativos que se dão entre representantes e representados nas redes sociais online.

\section{A lógica populista na comunicação e sua potencialidade em ambientes online}

Se atentarmos à dimensão discursiva do fenômeno populista, como Laclau (2010), podemos abordar diferentes relações entre populismo e comunicação política, como destacado por Engesser et al. (2017). Dentro desse recorte, compreende-se que, enquanto ideologia, o estudo sobre comunicação populista verificará o seu conteúdo; enquanto estilo, verificará seu formato; enquanto estratégia, verificará sua justificativa - o porquê de ser utilizado como meio para um fim.

Os trabalhos podem, ainda, investigar quem se coloca como enunciador desse discurso populista. Especificamente sobre a comunicação online, pode-se verificar quem utiliza os canais digitais exatamente para disseminar o discurso populista. Ou seja, identificar os atores ou líderes políticos que tendem a utilizá-lo nesses meios. Essas quatro perspectivas são combinadas pelos autores enquanto dimensões que eles identificam como uma lógica da comunicação do populismo, que pode ser entendida como o conjunto de normas, rotinas e procedimentos que moldam a comunicação populista (ENGESSER et al., 2017: p. 1280). O quadro 1, abaixo, sumariza essa caracterização.

\section{Quadro 1 - Dimensões e características da lógica da comunicação no populismo}

\begin{tabular}{|l|l|l|}
\hline Dimensão & Objeto & Características \\
\hline Ideológica & $\begin{array}{l}\text { Conteúdo do } \\
\text { discurso }\end{array}$ & $\begin{array}{l}\text { Nós versus Eles; Povo versus Elite; Inclusivo ou } \\
\text { separatista; Imediatismo; }\end{array}$ \\
\hline De estilo & $\begin{array}{l}\text { Formato do } \\
\text { discurso }\end{array}$ & $\begin{array}{l}\text { Retórica; Linguagem simples, negativa e emocional; } \\
\text { Irracional; De identificação; Personalista; }\end{array}$ \\
\hline
\end{tabular}


Fernanda Cavassana de Carvalho Emerson Urizzi Cervi

\begin{tabular}{|l|l|l|} 
Estratégica & $\begin{array}{l}\text { Justificativa do } \\
\text { discurso }\end{array}$ & Obtenção de poder; Mobilização; Legitimidade; \\
\hline Difusão & $\begin{array}{l}\text { Enunciador do } \\
\text { discurso }\end{array}$ & $\begin{array}{l}\text { Líder carismático; Sem mediações; Sem a presença de } \\
\text { instituições tradicionais como canais; }\end{array}$ \\
\hline
\end{tabular}

Fonte: Autores, a partir de Engesser et al. (2017), Laclau (2010), Canovan (1999) e Kögl (2010).

São, portanto, nas dimensões expostas no quadro 1 que a comunicação online pode servir ao populismo enquanto discurso favorecido pelas relações mais horizontalizadas e diretas entre os que emitem e os que recebem os discursos. Para Engesser et al. (2017), a comunicação populista é proeminente em determinados contextos sociais em que há oportunidade de difusão de discursos específicos, moldados por características próprias, como as resumidas acima. Os autores chegam ao âmbito online ao considerarem que a internet é correlacionada à lógica da comunicação populista já que, muitas vezes, ambas são exploradas sob a justificativa de defesa pela soberania populariv. Eles estão, portanto, considerando o potencial de democratização da internet - e assim a proximidade do populismo com a própria democracia como Canovan (1999) - e a dualidade povo versus elite - como ocorre em Laclau (2010). Assim, eles convergem a lógica da comunicação populista com a estrutura dos ambientes e das plataformas digitais.

Do ponto de vista ideológico, Engesser et al. (2017) afirmam, como Laclau (2010), que o populismo considera a elite como principal oponente do povo. Contudo, há de se considerar os "outros", que seriam demais grupos sociais, em um mesmo nível hierárquico social ao povo. Para Abts e Rummens (2007: p. 418), a lógica da identificação justifica a verticalização das relações no populismo, que irá distinguir o nós e os eles, mas essa lógica está presente na política democrática como um todo, não se restringindo aos fenômenos populistas. Aqui, a Internet serve à lógica populista pelas características que levam os ambientes digitais à "homofilia", ao reunir "iguais" em grupos e distinguilos, como os filtros de conteúdo de interesse gerados pelo efeito bolha e a redundância e fortalecimento de discurso a partir das câmaras de eco (ENGESSER et al., 2017).

Sobre o estilo da comunicação populista, ressaltam-se características como o uso de uma linguagem simples, emocional e negativa (ENGESSER et al., 2017, p. 1285). Canovan (1999) identifica a redução da complexidade do discurso como uma das primeiras estratégias de um líder populista, de forma a se aproximar do povo. A partir disso, Engesser et al. (2017) discorrem sobre como a literatura registra raiva, medo, ressentimento e esperança como algumas das emoções presentes na comunicação populista, o que foi aprofundado a partir de Laclau (2010). Já a negatividade, segundo os autores, é evidenciada ao colocar os oponentes - no caso "a elite" - como uma ameaça à soberania popular e traçar uma imagem negativa deles ao povo. Essas características também podem ser potencializadas na web, em especial em redes de relacionamentos.

Considera-se que a comunicação online já era caracterizada pela simplificação da linguagem, mais coloquial e sem formalismos (BARBOSA, 2004). Por sua vez, as redes sociais online (RSO) potencializam especialmente o caráter emotivo e negativo da comunicação digital. Isso é consequência do comportamento das pessoas nesses ambientes, mas evidenciados também pelos affordances das ferramentas. Podemos definir affordance como os recursos próprios do ambiente em que se dão os fluxos de comunicação e que estimulam determinadas ações, moldando o comportamento e a interação naquele espaç̧o vii (GIBSON, 1986). A distância física, o anonimato, a facilidade de publicação e difusão de opiniões, por exemplo, são affordances de RSO, que acabam por servir a um debate agressivo entre aqueles que interagem (HALPERN; GIBBS, 2013).

Hoje, a literatura dedicada ao âmbito online acaba se dividindo entre os otimistas e os pessimistas sobre os efeitos e as consequências da internet para a comunicação política e pública. Os otimistas acreditaram que a internet revigoraria a democracia, estimularia o debate público, plural e progressivo, crendo, inclusive, na formação de uma nova esfera pública (SCHÄLER, 2015). Essa foi uma visão apresentada por autores mais populistas na ótica de Bimberviii (1998), que previram transformações políticas a partir da Internet no final do século XX. Já os pessimistas percebem os ambientes online de modo oposto, já que suas características contrariariam o ideal deliberativo e dialógico ao reunir em grupos as pessoas like-minded, que compartilham das mesmas opiniões, tendendo mais à polarização (WOJCIESZAK; MUTZ, 2009). Contudo, os resultados empíricos levam os 
trabalhos a terem uma perspectiva mais agonística sobre o seu uso na comunicação política (SCHÄLER, 2015).

Sobre os atores, enunciadores do discurso populista, destaca-se que a Internet amplia a conexão personalista e a proximidade do líder carismático com o seu público, pois os atores discursam, especialmente via RSO, diretamente aos seus seguidores. Como é o caso do Twitter, rede social, classificada como um microblog, que se apresenta mais personalista que as demais e é utilizada pelos atores políticos para se dirigir diretamente aos seguidores por meio de textos curtos, de linguagem direta. Além disso, as redes sociais digitais têm fundido cada vez mais as esferas públicas e privadas dos cidadãos e dos atores políticos (COLEMAN, 2005).

Ressalta-se que a importância das tecnologias de mídia para a comunicação mais direta, personalista, entre o líder político e seus representantes é uma das características da democracia de público diagnosticada por Manin (1997). Contudo, também é importante ressaltar que as considerações de Manin (1997) sobre as transformações no governo representativo não foram aprofundadas diante da comunicação online promovida pela Internet, tampouco por suas redes sociais. Além disso, perfis nas RSO são um canal ainda mais direto de comunicação à disposição dos políticos, independente do jornalismo ou outras formas de comunicação midiática (ERNST et al., 2017). RSO como Facebook e Twitter ainda permitem uma comunicação constante e permanente entre líder e liderados, não-restrita ao período de campanha. São, portanto, ambientes potenciais para o desenvolvimento de campanhas permanentes online para legitimação das ações dos representantes (LARSSON, 2016).

Um ator político contemporâneo que se destacou no Twitter durante sua campanha eleitoral foi o atual presidente dos Estados Unidos, Donald Trump. Segundo Cowls (2017), o Twitter deve ser compreendido como a essência da comunicação populista de Trump e não apenas um canal utilizado para difundir um discurso populista. A RSO, nesse caso, foi fundamental para Trump formular uma comunicação populista paranoicai ${ }^{\text {ix }}$ cuja articulação "nós [a américa] contra eles" explorou sentimentos exagerados, de desconfiança e conspiração em seu discurso como candidato, explorando ferramentas da plataforma como as mobilizadoras hashtags (Cowls, 2017).

Já sobre a dimensão de estratégia, Engesser et al. (2017) pontuam que a lógica populista da comunicação pode atender a três principais objetivos: poder, mobilização e legitimidade. Novamente, a Internet e, ainda mais, as RSO são consideradas como uma variável que pode potencializar essa dimensão estratégica. Visando ao poder, são exemplos os atores que recorrem ao discurso populista para questionar o sistema institucionalizado ou atores em campanha, como era o caso de Trump (COWLS, 2017). O discurso crítico às instituições e elites políticas tradicionais coloca Trump como um exemplo de ator populista. A relação direta entre ele e os eleitores, via Twitter, posiciona-o como um tipo de representação personalista. A independência das instituições tradicionais para ativar os sentimentos do povo é o que une o líder populista ao discurso personalista.

A potencialidade online se destaca na dimensão estratégica, especialmente do ponto de vista da mobilização. Isso tanto por se apresentar como um ambiente propício para a formação de massas não institucionalizadas, suscetíveis a essas estratégias (ENGESSER et al., 2017: p. 1286), quanto por outras características próprias às plataformas e ao comportamento online, já mencionadas anteriormente. A literatura já ressalta a mobilização como a principal finalidade do Facebook na comunicação política (MAIA, REZENDE, 2015; BRUGNANO, CHAIA, 2014). Isso se dá justamente pela elevada capacidade viral da RSO com suas affordances para o compartilhamento de conteúdos políticos ${ }^{\mathrm{x}}$.

A definição de "grupos-alvos" é destacada como especialmente fértil à lógica da comunicação populista. Eles são delimitados por interesses comuns e preferências ideológicas. Assim como Laclau (2010) disserta sobre a lógica de constituição de grupos homogêneos por indivíduos que se identificam na esfera digital, essa formação aproxima-se muito mais da realidade de grupos distintos do que uma única massa, homogênea. Ernst et al. (2017) reforçam a importância da formação de grupos específicos na Internet, para os quais o líder pode se dirigir de forma estratégia, identificando os seus "semelhantes" e os "outros".

Pertinente a isso, Sorj (2015) verifica alterações do comportamento social, especialmente ao que se relaciona à organização e à atuação política da população na esfera digital. Para ele, a mobilização online se caracteriza de modo distinto das demais ondas de civilidade social. Ao invés de, primeiramente, reunir pessoas que se identificavam em grupos, para depois se manifestarem juntos, como ocorria anteriormente, hoje, as associações em grupos virtuais são formadas pela proximidade dos conteúdos manifestos online. Essa conduta social acaba por valorizar mais uma heterogeneidade de 
comportamentos, bem como uma pluralidade de demandas, mais particulares. Isso afasta a Internet de ser caracterizada como um ambiente de massa homogênea, mas reforça o potencial mobilizador da comunicação online, em comparação à tradicional, para os grupos aos quais ela será direcionada. Ou seja, a comunicação via Internet fortalece e amplia grupos, delimitados e coesos, que, separadamente, podem ser mobilizados.

Como o discurso populista também pode ser instrumentalizado pelos atores políticos como estratégia para garantir legitimidade de suas ações (ABTS e RUMMENS, 2007; CANOVAN, 1999; LACLAU, 2010), defende-se que o populismo na perspectiva discursiva pode ser explorado pelos atores políticos mesmo depois da obtenção do poder. Isso é mais evidente nos casos presidencialistas, em que os líderes são mais dependentes do apoio direto (ENGESSER et al., 2017: p. 1286) e tendem explorar a lógica da comunicação populista para se direcionarem diretamente aos seus representados. 0 que, portanto, pode ser garantido via RSO como Twitter e Facebook quando utilizados pelos líderes por meio de um estilo personalista.

Uma pesquisa recente que ressalta as características das mídias sociais para atender à lógica populista e verifica, empiricamente, tais estratégias é a de Ernst et al. (2017, p. 4). Para os autores, há quatro características principais dessas plataformas que reforçarão a lógica da comunicação populista. Em primeiro lugar, como os atores populistas requerem um acesso sem mediações com a população, essas plataformas garantem uma conexão direta, sem gatekeepers ${ }^{x i}$ institucionais, dependência da visibilidade via imprensa e sem interferência publicitária. A presença social garantida pelas redes também reforça o aspecto de proximidade do representante com seus representados, pois ele pode se conectar de forma mais humanizada, criando laços, inclusive.

Na busca por características populistas na comunicação de líderes políticos contemporâneos em RSO, por exemplo, Ernst et al. (2017) consideraram as publicações no Twitter e no Facebook de diversos atores políticos e partidos, em seis países ocidentais. Por meio de uma análise multivariada, que considerou categorias de classificação dos partidos e de estratégias da comunicação política nas mensagens publicadas, os autores consideraram três principais aspectos por meio de análise do conteúdo: i) centralidade nas pessoas (se há a declaração de um povo forte e único, se há elogios às conquistas desse povo, se demonstra proximidade com as pessoas); ii) anti-elitismo (se acusam a elite, se desacreditam a elite, se desvinculam a elite do povo); e iii) a restauração da soberania popular (se exigem a soberania popular e se negam a soberania da elite). Os resultados indicam que há evidências significativas de que uma posição extrema do partido e um status de oposição favorecem o aumento do uso de comunicação populista via mídias sociais (ERNST et al., 2017).

Além disso, essas mídias sociais potencializam a personalização, por não se tratarem apenas da vida pública desses atores, mas também de sua esfera privada. Portanto, como apresentado acima, as características do populismo enquanto forma de comunicação podem ser potencializadas quando ela se dá nos ambientes online, em especial nas RSO. Como resumo do que foi discorrido até aqui, o quadro 2 indica, a seguir, as potencialidades da comunicação online por dimensão da comunicação populista, dialogando com o conteúdo da síntese anterior, exposta no quadro 1.

\section{Quadro 2 - Potencialidades do online para a lógica da comunicação no populismo}

\begin{tabular}{|l|l|l|}
\hline Dimensão & Objeto & Porque RSO podem potencializar a comunicação populista \\
\hline Ideológica & Conteúdo & $\begin{array}{l}\text { - As redes sociais tendem a criar grupos like-minded reunindo aqueles } \\
\text { que compartilham opiniões, valores e ideologias, intensificando a } \\
\text { polarização. } \\
\text { - O efeito bolha tende a distanciar grupos, cada vez mais coesos. }\end{array}$ \\
\hline De estilo & Formato & $\begin{array}{l}\text { A linguagem é coloquial e simples, direta e acessivel ao entendimento } \\
\text { comum. }\end{array}$ \\
$\begin{array}{l}\text { A comunicação nas RSO tende a ser emotiva e reativa às informações, } \\
\text { levandestaços negativas. } \\
\text { par ausência de racionalidade nas reações, marcadas principalmente } \\
\text { por mabjetivas. }\end{array}$ \\
\hline
\end{tabular}


Fernanda Cavassana de Carvalho Emerson Urizzi Cervi

\begin{tabular}{|l|l|l|}
\hline \multirow{5}{*}{ Estratégica } & Justificativa & $\begin{array}{l}\text { - Candidatos em campanha e outros atores políticos utilizam as RSO } \\
\text { para obter seguidores e ampliar seus discursos. } \\
\text { - A lógica de engajamento, interações e manifestações em rede } \\
\text { intensificam a mobilização. } \\
\text { - Representantes têm utilizado perfis nas RSO para desenvolver } \\
\text { campanhas permanentes que atendem à legitimidade de suas ações. }\end{array}$ \\
\hline Difusão & Enunciador & $\begin{array}{l}\text { - A comunicação com os representados nas redes sociais é direta, sem } \\
\text { mediações, e personalista, tendendo a caracterizar-se como mais } \\
\text { íntima, mais próxima da esfera privada do líder. } \\
\text { - Fluxos de comunicação online são horizontais e de dupla direção. A } \\
\text { maior interação intensifica a relação direta entre representantes e } \\
\text { representados. }\end{array}$ \\
\hline
\end{tabular}

Fonte: Autores, a partir de Engesser et al. (2017) e Ernst et al. (2017).

Ressalta-se que compreender as características da lógica da comunicação populista hoje nos ambientes digitais pode abranger outras perspectivas, inclusive não restritas ao discurso da liderança, sejam indivíduos ou partidos. Portanto, não se trata apenas de pensar em uma representação na perspectiva da democracia de público de Manin (1997). Como essas novas ferramentas são caracterizadas pela interatividade e por fluxos comunicativos horizontais, em duplo sentido, a discussão sobre as características da lógica populista de comunicação entre os líderes e seu público-alvo deve considerar também o conteúdo publicado pelos cidadãos, que se manifestam nas RSO, muitas vezes em resposta aos políticos.

Uma das formas de aproximar a discussão clássica de retórica populista das conversações em RSO é a partir do conceito de democracia monitorada. Para Keane (2010), trata-se de um novo estágio histórico das sociedades democráticas, em que há uma reconfiguração dos espaços do Estado e das relações entre as diferentes esferas políticas e sociais. $O$ autor defende que as democracias representativas passaram por alterações ao longo de períodos de consolidação, contudo, nenhuma foi tão decisiva quanto essa nova fase de monitoramento, que marca mudanças no contorno e na dinâmica da própria democracia. O monitoramento da democracia se dá em diferentes dimensões, por diversas formas e atores, coletivos e individuais, institucionais ou não, da sociedade e da própria dimensão do Estado. Monitorar pode ser compreendido como a ação sistemática de vigília e fiscalização de algo ou alguém (KEANE, 2010). A consequência do monitoramento é a crítica pública direta à instituição representativa e não ao objeto de representação. Assim, a simples existência de monitor social indica uma queda na capacidade representativa das instituições políticas.

O monitoramento democrático é justamente a ação de acompanhar e cobrar os representantes, tanto da sociedade, quanto do campo político. É claro que o monitoramento por parte da sociedade também é importante para a dimensão participativa do cidadão (SCHUDSON, 1998), mas a partir da discussão apresentada por Keane (2010), é possível considerar que o excesso de participação do tipo monitor (dada sua direção e finalidade crítica) pode levar a um desgaste representativo. Isso quer dizer que o excesso de cobrança, sem mediações e de forma desorganizada, pode enfraquecer os representantes monitorados - sejam atores ou instituições. Keane (2010: p. 619) ressaltará, por exemplo, que políticos, partidos e governos eleitos passam a atuar sob alerta permanente. Com isso, os monitores questionam a autoridade dos representantes e podem fazer com que eles mudem inclusive suas agendas. Por isso, para o autor, essa nova fase das democracias é 'pósrepresentativa'. Nela, toda e qualquer forma de poder está sujeito à contestação do público (KEANE, 2010).

É importante destacar que Keane (2010) não defende que as democracias se tornarão participativas. Ao contrário disso, ele ressaltará a relevância da representatividade e do funcionamento das instituições para a manutenção da democracia, inclusive em sua fase monitorada. Isso inclui a 
MAIS POPULISMO, MENOS

REPRESENTATIVIDADE: MONITORAMENTO

E LÓGICAPOPULISTA DA COMUNICAÇÃO

POLITITA EM REDES SOCIAIS ONLINE

Fernanda Cavassana de Carvalho Emerson Urizzi Cervi

mediação do debate público, que na perspectiva de Keane (2010) passa a contar com um maior número de fluxos comunicativos e atores produzindo e consumindo informações ${ }^{\text {xii }}$. Assim como no populismo, esses fluxos são diretos, horizontais e sem mediações.

A democracia monitorada está estreitamente ligada ao crescimento de sociedades saturadas de múltiplos meios de comunicação, segundo o autor. O cenário informacional das democracias contemporâneas é de excesso de informação e de formas de comunicação. De acordo com Keane (2010), a comunicação online alimenta o comportamento de monitoramento dos representantes ao possibilitar a redistribuição de informações, avaliações e críticas sobre atores e casos políticos, inclusive de modo viral. Mas, em excesso, essa prospecção leva à confusão. Portanto, a comunicação online satura ainda mais o debate público, ampliando as cobranças e demandas às instituições de representação.

A aproximação dessa teoria de Keane (2010) com o que foi discutido pela perspectiva do fenômeno político populismo se dá em pelo menos cinco aspectos. Primeiramente, tanto o populismo quanto a democracia monitorada têm o mesmo ponto de partida, pois são baseados em crise de representatividade e desconfiança das instituições democráticas. Pode-se compreender que a insatisfação com a organização política da sociedade está presente e pode ser causa dos dois fenômenos que representam desgastes nas democracias contemporâneas, representativas.

Um segundo aspecto de aproximação da teoria de Keane (2010) com a perspectiva populista é que essas novas instituições de monitoramento são criadas com um apelo massivo. $O$ autor destacará que novos monitores sociais surgem a todo momento "em nome do povo". Uma terceira aproximação se dá no aspecto temporal. Assim como o populismo possui uma retórica ancorada no imediatismo (LACLAU, 2010), na democracia monitorada tudo é muito rápido: a desconfiança, a saliência no debate público, a cobrança e a necessidade de resposta sobre as demandas apresentadas.

Em quarto lugar, tanto o populismo quanto o monitoramento das democracias são apoiados e se fortalecem a partir da comunicação política. Assim como há a lógica própria de comunicação populista, o monitoramento das democracias no estágio apresentado por Keane (2010) só é possível pela abundância comunicativa. Por fim, essa desconfiança das instituições representativas, exposta e fortalecida por tipos específicos de comunicação política passa a ser potencializada no âmbito das redes sociais online (RSO). Todas as características elencadas no quadro 2 , que potencializam a lógica populista na comunicação online, também servem para expandir e fortalecer o monitoramento dos representantes por parte de seus representados.

Aqui, a relação entre a dimensão discursiva do populismo e monitoramento institucional se dá na medida da participação direta dos comuns, integrantes do povo, ao criticar a atuação de instituições convencionais da democracia representativa. Ao mesmo tempo em que enfraquecem a capacidade representativa tradicional, os monitores abrem espaço para o crescimento de uma liderança que fale em nome do povo, diretamente para as pessoas comuns, utilizando para isso ferramentas típicas de redes sociais online.

\section{Conclusões}

Este artigo partiu de uma discussão sobre o conceito de populismo, enquanto processo de formação política, para se centrar em uma de suas dimensões - a discursiva - e tratar da mesma a partir do cenário digital de comunicação, protagonizado pelas redes sociais online (RSO) na contemporaneidade. Teve como principal aporte teórico o trabalho de Laclau (2010), que discorre sobre as relações políticas entre os representantes e representados e evidencia como uma de suas características a falta racionalidade nessas relações.

Seguindo as ponderações de Laclau (2010), reforça-se que são as relações entre os representantes e representados desprovidas de racionalidade. Uma vez criado o vínculo por meio da retórica e da identificação, ao voltarmos para a comunicação entre as partes, será possível verificar e observar a articulação de palavras e símbolos genéricos. As mudanças tecnológicas e mercadológicas 
das plataformas tecnológicas também contribuem para isso. Não só por seus affordances, discutidos anteriormente, mas também quando se consideram os formatos e o próprio comportamento de consumo de informações. Também destacamos a diferença entre dimensão discursiva populista e relações personalistas de representação política.

Além disso, buscou-se apresentar como a comunicação populista segue uma lógica em diferentes dimensões: ideológica, estratégica, de estilo e de difusão. Assim, o populismo enquanto forma de comunicação pode emergir em diferentes sociedades e governos, de esquerda ou de direita, desde que seja latente o descontentamento social diante da esfera política, desconfianças nas instituições representativas e que haja um líder que se dirija retoricamente ao povo.

O trabalho abordou como as características da comunicação online contribuem para potencializar uma lógica populista da comunicação política. Contudo, é importante destacar que essa lógica não se dá apenas do líder em direção ao seu grupo de liderados, uma vez que compreendemos que ela pode ser aplicada em outros processos comunicativos, dados os fluxos horizontais dos mesmos. Aqui, defende-se como comentários conclusivos que, ao considerar o populismo uma forma de representação, suas características comunicativas são reforçadas pelo próprio público, não sendo restritas ao líder enquanto enunciador discursivo, emissor da mensagem. Isso é especialmente evidenciado quando se consideram as atuais formas de comunicação nas democracias monitoradas.

A discussão sobre as características das relações comunicativas entre os representantes e representados também dialoga com a perspectiva teórica de Keane (2010), ao tratar das democracias monitoradas, o que foi aprofundado no tópico anterior deste artigo. Para autor, as democracias se modificaram e tornaram-se monitoradas por diversas instituições e atores independentes, que aprenderam que devem cobrar e julgar suas instituições e representantes. Essa atuação coloca as instituições políticas e sociais representativas sob constante alerta, enfraquecendo-as. Assim como a lógica da comunicação populista, este cenário de monitoramento é potencializado nos ambientes digitais. Portanto, o que se argumenta aqui é que: i) a ausência de racionalidade na retórica do discurso populista; ii) a lógica da comunicação populista em suas diferentes dimensões; iii) a comunicação online e iv) prática de monitoramento comungam de algumas características que potencializam o enfraquecimento das relações representativas nas sociedades democráticas.

Em suma, trabalhos que se dedicaram a observar a comunicação política em ambientes virtuais, especificamente nas RSO, indicam que o debate digital tende à polarização e à formação de câmaras de eco (WOJCIESZAK; MUTZ, 2009). Isso contribui também para a potencialidade da comunicação emotiva. Além disso, já se sabe que esse fenômeno, que inclui o debate entre o público e dele com a elite e com as instituições políticas, dá-se em grande volume e intensidade, mas sem resultados práticos de fato. E isso não se dá somente na relação entre os representantes e representados, mas também internamente entre aqueles que se agrupam, por se reconhecerem e se identificarem naquele grupo.

Assim, esses ambientes digitais se mostram, cada vez mais, propícios às lógicas populistas da comunicação. Ressalta-se que, por mais que as plataformas online potencializem e estimulem a participação política, inclusive permitindo novos espaços que aproximam os cidadãos de seus representantes, reforça-se que somente ambientes regrados e, portanto, institucionalizados, tendem a garantir resultados e efeitos políticos de fato (SCHÄFER, 2015).

É relevante destacar que distante de um determinismo tecnológico, as relações políticas online tendem a refletir a política tradicional, seus fenômenos, suas lógicas de estruturação e organização, bem como o comportamento dos seus atores. São as crises de representatividade verificadas nas democracias contemporâneas que também passam a ser ilustradas pelas relações em ambientes digitais, onde os cidadãos passam a monitorar e a questionar seus representantes, tanto instituições quanto líderes (KEANE, 2010), potencialmente por meio da comunicação online (ENGESSER et al., 2017) e, especialmente, daquela que se dá via redes sociais.

(Recebido para publicação em janeiro de 2018)

(Reapresentado em maio de 2018)

(Aprovado para publicação em junho de 2018) 
MAIS POPULISMO, MENOS

REPRESENTATIVIDADE: MONITORAMENTO

E LÓGICAPOPULISTA DA COMUNICAÇÃO

POLIITICA EM REDES SOCIAIS ONLINE

Fernanda Cavassana de Carvalho Emerson Urizzi Cervi

\section{Cite este artigo}

CARVALHO, Fernanda Cavassana; CERVI, Emerson Urizzi. Mais Populismo, Menos Representatividade: Monitoramento e Lógica Populista da Comunicação Política em Redes Sociais Online.

Revista Estudos Políticos: a publicação semestral do Laboratório de Estudos Hum(e)anos (UFF). Rio de Janeiro, Vol. 9 |N.1, pp. 86 -103, julho de 2018. Disponível em: http://revistaestudospoliticos.com/

\section{Notas}

1. Redes sociais online são mídias sociais que permitem a publicação de conteúdos (públicos, privados, políticos, mercadológicos, etc.) e o relacionamento entre perfis vinculados nesses ambientes. São caracterizadas essencialmente pela interação e têm sido exploradas pelas pessoas e instituições, inclusive políticas. Em formato, apresentam-se como sites ou aplicativos para dispositivos móveis. São exemplos contemporâneos: Facebook, Twitter, Linkedin, Instagram, Snapchat.

2. "Advocates of populism conceptualize democracy first and foremost as the direct rule of the people and, therefore, tend to identify populism with democracy. Opponents of populism, on the other hand, hold a more constitutional conception of democracy, emphasizing the importance of representation, individual rights and the balancing of powers and interests" (ABTS, RUMMENS, 2007, p. 406).

3. Para viabilizar os estudos empíricos Kögl (2010) propõe: i) constituir um tipo de ideal para mensurar empiricamente graus e intensidades de aproximação ao modelo ideal; ii) definir um aspecto analítico específico dentre as várias características atribuídas ao populismo e restringir a pesquisa a essa única dimensão. Sobre os diferentes modelos, separa-os em três principais abordagens: fenomenologia-descritiva, empíricoindutivo e discursiva.

4. A revisão bibliográfica de Laclau (2010) considera autores clássicos da segunda metade do século XIX, especialmente sobre as teorias das massas. Trabalha com Wiles, Minogue, Canovan, Makoe, Worsley, Taine, Le Bon e Tarde.

5. Apesar dessa defesa, Laclau $(2010$, p. 88$)$ pondera que Freud parte de estudos genéticos, adequados à psicologia, sendo necessário adaptar tais variáveis e categorias para o campo sociopolítico.

6. "In summary, populism and the Internet have in common that they both have been regarded as correctives of democracy" (ENGESSER et al., 2017, p. 1283).

7. Os botões interativos de plataformas como Facebook e Twitter, como compartilhar e retuitar respectivamente, e curtir e marcar outro usuário em uma publicação em ambos são 
MAIS POPULISMO, MENOS

REPRESENTATIVIDADE: MONITORAMENTO

E LÓGICAPOPULISTA DA COMUNICAÇÃO

POLIITICA EM REDES SOCIAIS ONLINE

Fernanda Cavassana de Carvalho

Emerson Urizzi Cervi

affordances desses ambientes que estimulam uma interação com recirculação de conteúdos.

8. Bimber (1998) disserta sobre duas principais correntes teóricas em ascensão no final do século XX que traziam afirmações sobre efeitos da Internet para mudanças políticas, uma populista e outra comunitária. A primeira reforçando a perda de força das elites e instituições e a outra indicando mudanças de sentido de comunidade enquanto agrupamento social.

9. Cowls (2017) investiga a ascensão de Donald Trump ao governo americano utilizando o Twitter como ferramenta de comunicação populista. Em sua tese, o autor trabalha com o conceito de "populismo paranoico", entendendo a paranoia como um estilo político embasado na desconfiança, nas ideias de conspiração e no exagero, explorado independentemente do espectro ideológico. Cowls defenderá que a paranoia e o populismo, em sua dimensão comunicativa, compartilham características como o próprio discurso nós contra eles.

10. Bennett e Segerberg $(2012$, p.753) destacam que os compartilhamentos em redes como o Facebook não servem apenas à lógica da ação coletiva convencional, mas permitem o compartilhamento de perspectivas individuais que complementam as mensagens mobilizadoras, tornando a mobilização em RSO como uma estrutura organizacional autoestruturada.

11. Controladores dos fluxos comunicativos. Mediadores que delimitam o conteúdo que passa pelos "portões" até o público. Ou seja, controladores do acesso e da difusão de conteúdos.

12. É importante destacar que para Keane (2010) o estágio de monitoramento democrático se inicia com o fim da Segunda Guerra Mundial. Portanto, aproxima-se das considerações de Manin (1997) sobre a democracia de público ao considerar o fortalecimento da comunicação de massa ao longo do século $X X$. Contudo, os fluxos comunicativos importam em Keane (2010), principalmente oriundos dos cidadãos aos representantes, e não apenas pensar na comunicação dos representantes em um palco à sua audiência, como posto por Manin (1997). É justamente pela potencialidade de interação e de fluxos oriundos da sociedade é que a comunicação online via redes sociais importa na perspectiva de Keane (2010).

\section{Bibliografia}

ABTS, Koen; RUMMENS, Stefan. "Populism versus Democracy". Political Studies, 2007, vol. 55, pp.405-424.

BARBOSA, Ana Cristina L. S. Leitura e escrita na web. Linguagem em (Dis)curso, v. 5, n. 1, p. 153-183, 2004. 
MAIS POPULISMO, MENOS

REPRESENTATIVIDADE: MONITORAMENTO

E LÓGICAPOPULISTA DA COMUNICAÇÃO

POLIITICA EM REDES SOCIAIS ONLINE

Fernanda Cavassana de Carvalho Emerson Urizzi Cervi

BENNETT, W. Lance; SEGERBERG, Alexandra. The Logic of Connective Action. Information, Communication \& Society. 15:5, 2012, pp.739-768

BIMBER, Bruce. The internet and political transformation: populism, community and accelerated pluralism. Polity, vol.31, no.1, pp.133-160, 1998.

BLOCK, Elena; NEGRINE, Ralph. The populist communication style: Toward a critical framework. International Journal of Communication, vol. 11, p. 20, 2017.

BRUGNANO, Fabricio; CHAIA, Vera Lucia. "A nova polarização política nas eleições de 2014: radicalização ideológica da direita no mundo contemporâneo do Facebook". Aurora. Revista de Arte, Mídia e Política, 2014, vol.7, no.21, pp.99-129.

CANOVAN, Margaret. "Trust the people! Populism and the two faces of democracy". Political Studies, 1999, vol.47, no.1, pp.2-16.

COLEMAN, Stephen. "New mediation and direct representation: reconceptualizing representation in the digital age". New Media \& Society, 2005, vol.7, no. 2, pp.177-198.

COWLS, Josh Joshua Nicholas. From Trump Tower to the White House, in 140 characters: the hyper-mediated election of a paranoid populist presidente. Doctoral dissertation, Massachusetts: Massachusetts Institute of Technology, 2017.

ENGESSER, Sven; FAWZI, Nayla; LARSSON, Anders Olof. "Populist online communication: introduction to the special issue". Information, Communication \& Society, 2017, vol.20, no.9, pp. 1279-1292, DOI:

$10.1080 / 1369118 X .2017 .1328525$.

ERNST, Nicole; ENGESSER, Sven; BÜCHEL, Florin; BLASSNIG, Sina; ESSER, Frank Esser. "Extreme parties and populism: an analysis of Facebook and Twitter across six countries". Information, Communication \& Society, 2017, vol.20, no9, DOI:

10.1080/1369118X.2017.1329333.

FUNES, Patricia. Historia mínima de las ideas políticas en América Latina. Madrid: Turner publicaciones, 2014.

GIBSON, J. J. The ecological approach to visual perception. Hillsdale, NJ: Lawrence Erlbaum Associates Inc., 1986.

HALPERN, D.; GIBBS, J. "Social media as a catalyst for online deliberation? Exploring the affordances of Facebook and YouTube for political expression.". 
MAIS POPULISMO, MENOS

REPRESENTATIVIDADE: MONITORAMENTO

E LÓGICAPOPULISTA DA COMUNICAÇÃO

POLÍTICA EM REDES SOCIAIS ONLINE

Fernanda Cavassana de Carvalho Emerson Urizzi Cervi

Computers in Human Behavior, 2013, vol.29, no.3, pp.1159-1168.

HERMET, Guy. "El populismo como concepto". Revista de Ciencia Politica, 2003, vol. 23, no.1, pp.5-18.

JAGERS, Jan; WALGRAVE, Stefaan. "Populism as political communication style. An empirical study of political parties' discourse in Belgium" European Journal of Political Research, 2007, vol.46, no.3, pp.319-345. DOI: 10.1111/j.1475-6765.2006.00690.x

KEANE, John. Vida e Morte da Democracia. São Paulo: Edições 70, 2010.

KÖGL, Irene. "A clash of paradigms: populismo and theory building". Revista Sociedade e Cultura, 2010, vol.13, no.2.

LACLAU, Ernest. La razón populista. Buenos Aires: Fondo de Cultura Económica, 2010.

LARSSON, Anders Olof. Online, all the time? A quantitative assessment of the permanent campaign on Facebook. New Media \& Society, v. 18, n. 2, p. 274-292, 2016.

LE BON, Gustave. The crowd: A study of the popular mind. New Brunswick y Londres, Transactions Publishers, 1995.

MAIA, Rousiley; REZENDE, Thaiane. Democracia e a ecologia complexa das redes sociais online: um estudo sobre discussões acerca do racismo e da homofobia. Intexto, 2015, no.34, pp. 492-512.

MANIN, Bernard. The principles of representative government. Cambridge University Press, 1997. SCHÄFER, M. "Digital Public Sphere". In: MAZZOLENI, Gianpietro et al. (ed.). The International Encyclopedia of Political Communication, John Wiley \& Sons, 2015.

SCHUDSON, M. The good citizen: A history of American civic life. Free Press, 1998.

SORJ, B. "On-line/off-line: a nova onda da sociedade civil e a transformação da esfera pública". In: SORJ, B., FAUSTO, S. (Orgs.) Internet e mobilizações sociais. São Paulo: Edições Plataforma Democrática, 2015.

WEYLAND, K. (2001). Clarifying a Contested Concept: Populism in the Study of Latin American Politics. Comparative Politics, 001, vol.34, no.1, pp.1-22. DOI: $10.2307 / 422412$.

WORSLEY, Peter. "O conceito de populismo". In: TABAK, Fanny (org.). Ideologias - Populismo. Rio de janeiro:

Eldorado, 1973. 
MAIS POPULISMO, MENOS

REPRESENTATIVIDADE: MONITORAMENTO

E LÓGICAPOPULISTA DA COMUNICAÇÃO

POLIITICA EM REDES SOCIAIS ONLINE

Fernanda Cavassana de Carvalho

Emerson Urizzi Cervi

WOJCIESZAK, Magdalena; MUTIZ, Diana. "Online Groups and Political Discourse: Do Online Discussion Spaces

Facilitate Exposure to Political Disagreement?". Journal of Communication, 2009, vol.59, pp.40-56. 